\title{
Interaction of Virtual and Physical Space in Contemporary Urban Design
}

\author{
Mir Saeed Moosavi
}

\begin{abstract}
Predicting the environment people will be living in during the next millennium is not easy task, even at all possible. Film makers continually portray baffling urban decay where chaos takes over amidst convulsive and apparently uncontrollable growth. When this is coupled with a grotesque transformation of human relationships -the consequence of a generalized mistrust in mankind's capacity to cope with the many implications that are the result of radical modifications to interpersonal communication and the introduction of the " virtual dimension of being”- one can only feel disconcerted. Undoubtedly, we are going to encounter virtual space in combination with the physical space during the next millennium.

We are more familiar with physical than with virtual space both as users and as practitioners. Physical space is the material object of spatial planning and urbanism. It comprises, traditionally, zones adapted to activities and channels of communication providing links between zones, catering to transport or various types of buildings, if one includes architecture. Physical space, by the way, covers both urban and rural space. Virtual space, on the other hand, is less familiar and has a confined application. The vocabulary which partly explains the frequent use of spatial metaphors to describe it are: web site, information superhighway or electronic highway, teleport, virtual community or electronic neighborhood, virtual or digital cities, the city of bits, etc. These spatial metaphors need to be handled with caution as they tend to obscure issues or even turn into ideologies. Spatial metaphors may tempt some people to escape from real-world urban problems into virtual "urban" space. Metaphors are to be avoided when the issue is how to deal with the interactions between physical and virtual space. In other words, they must be defined as distinct entities.

In this paper, the intention is to analyze the meaning of virtual and physical space and their interaction in the contemporary urban planning and design.
\end{abstract}

Index Terms — physical, space, virtual, urban planning

\section{INTRODUCTION}

I $\mathrm{N}$ the mid- $20^{\text {th }}$ century, those thinking about cities believed that they were clearly organized, simply ordered, and thus

M. S. Moosavi is with the Department of Architecture, Islamic Azad University of Tabriz, Tabriz, Iran. (phone: +98 411 5569930; fax:+98 411 3350363; e-mail:saeed_mtabriz@yahoo.com). predictable, capable of being designed and planned in such a way that the quality of life of their residents could be directly improved by manipulating their physical form. This was a view that was widely held throughout architecture, indeed throughout the social sciences. It was founded on the belief that the social world, and its representation in physical artifacts such as cities was coherent and understandable in the same way that the physical world had been understood since the Enlightment [1].

By the last decade of $20^{\text {th }}$ century a new type of urban life was created. The new situation which was the result of radical modifications of interpersonal communications, transformed the human relationships and led to the introduction of "virtual dimension of being". Advances in multimedia technology urged people to accept virtual relations as the new and most favorite type of communication. But some nations are still keeping their past traditions and the combination of virtual and real life is becoming more and more confusing.

Telecommunication, electronic environments, digital technology and global networks increasingly affect the physical world we live in. Rapid advances in this technology will overthrow the regime of time and space that are familiar to us today. It is constructing interactions and dialogues between two different realms, one is the physical reality with local identity, the other is the virtual reality of infinite construction site in cyberspace.

In developing countries like Iran, this interaction is more confusing and even problematic. Iran, a country with an old history and diverse traditions of urban life, now faces a global situation in which all traditions, localities and old believes must be ignored. New trends in younger generation and bias towards old traditions in older generation creates a gap between them. In order to deal with this contradiction and duality, the new generation of urban planners and designers must try to further reinforce the interaction between two different realms, one is the physical life, the other is virtual world. In order to reach this goal, the very first step is to understand the nature of virtual world and its relationship with physical life [2].

\section{II.VIRTUAL REALITY}

\section{Interpretation of Virtuality}

For the majority of theorists, virtuality describes the totality of effects and mutations brought about by the information and communication network. Virtuality designates not only 
whatever happens on, or is generated by the internet but also includes the impact of the media on the way in which we apprehend, represent and consequently build the world around us. By this definition, virtuality concerns the blurring of the distinction between perception and representation, original and copy [3]. Generally speaking, the virtual world is a computer-generated space which contains objects. These objects are usually defined by their form (geometry), attributes (color, appearance, associated sounds) and may have behavior rules (i.e. something happens when you touch them). To be of any use in practical VR applications, the user must be able to interact with the virtual world. As an absolute minimum, the user must be able to freely navigate, i.e. walk around, in this space. It gets more interesting when the user can interact with objects, like pressing a button to open a door, creating or moving objects or even take part in a multi-user simulation. A human experiences the world through the five senses. Vision is usually considered the most important sense, followed by hearing, smelling and touching. Even though our nose is a pretty sensitive organ, smelling has lost much of its importance in the civilization, so a VR world can usually do pretty well without serving it. The same applies to tasting.

A perfect feeling of immersion into the virtual world means that all senses have to be stimulated. The quality and level of the sensual experience determines if the user feels a part of the virtual environment or just as a spectator of a computer simulation.

One of the most important issues in immersive virtual reality is the consistency of the sensory stimulation. Our brain combines the input of the eyes, ears and balance into a global picture of the world. If the stimulations do not match, for example when you turn your head but the eyes always see the same, simulator sickness may quickly result. This is exactly the same effect as motion or seasickness where the eyes get a constant image but your body feels a movement. Once we have all ingredients together to build our virtual environment, we need to do something with it. Besides the obvious entertainment applications like games or exploration of virtual sites, there are quite a few useful tools already. VR is currently used a lot for simulation and training of situational awareness. As you can imagine, the military is a huge customer (and developer) of VR systems. There have also been some successful applications in psychiatric treatment such as training programs against fear of height or small spaces. Traditional data visualization also profits from immersive environments as it eases data analysis when users can really walk into the data. The oil and gas industry for example uses these environments for collaborative analysis of geological data. Another huge customer is the automobile industry. They use VR installations for design reviews as well as product design. Architectural walk-throughs are common as well.

\section{Virtual Architecture}

Architects have always needed somewhere to draw. History has seen dirt, stone, wood, and paper each serve in turn as the architect's medium. Every technological advance has helped to manifest these exploratory visions in ever-increasing fidelity, while influencing the way in which the design process is conducted. Computer technology is the latest step in this progression, adding a third dimension to the architect's drawings. Programs like $3 \mathrm{ds} \max ^{\mathrm{TM}}$ allow the architect to build lifelike models and take clients on fly-throughs. Now, virtual reality has advanced architectural drawing to "full body design", letting architects experience their creations, rather than just seeing those creations in front of them [4].

Computer technology and Virtual Reality generate a wonderful world of unfettered choices - the cyberspace, which enables you to feel the pleasure of making things that are impossible in the physical real, creating atmosphere that never imagined or experienced before, aspiring to Godlike status to control and manipulate the world. Within this phantasm dimension, your minds are allowed to be free, even momentarily away from the body, it gives you the ability of being oneself and being someone else, being here at this moment and on the other side of the screen in the next, an almost schizophrenic situation of the physical self.

However, we cannot surpass or bypass the physical space, we cannot avoid the uncontrollable messiness of the physical real. Only because of the existence of this micro-system of our cell-composed human bodies, can we have and also make it meaningful, the fascinations, imaginations, illusions, or even hallucinations of doing things impossible in the physical world. The digital technology offers us insights into our understanding of the relationships between ourselves and the world outside. A critical benefit of being able to evaluate a design at full-scale is that its spatial sequence may be examined. An architectural design is simultaneously the union of its pieces and the position and orientation of those pieces relative to each other. The continuity of this sequence is just as critical to a visually pleasing design as the appearance of the individual pieces. At the miniature scale of a model, it becomes nearly impossible to adequately scrutinize sequence, and the architect must use a liberal dose of imagination to picture the full-scale sequence. Virtual reality takes the guesswork out of this process and allows the spatial environment of a design to be explored in six degrees of freedom in its original scale. The architect can move from inside to outside, above to below, walk through walls, stand on the roof, or fly to any location for a bird's-eye-view. Movement and circulation can be evaluated from any location, and changes can be assessed in their global context.

\section{Virtual City}

The most striking transformation effected by digital technologies and telecommunication revolution is the change in our perceptions of materiality, space, and information, which is bound directly or indirectly to our understanding of architecture, habitation, the city and the entire built environment. This transformation emerged from the utopia of perfection, the nostalgia about the future and the desire for fantasy.

In contemporary world, the digital technology is applied to extend and maximize the desire for fantasy. It aims at meeting the increasing needs and rising expectations for quality of life and communal experience. It tends to modify the distinctions between material and immaterial, perfection and imperfection, mental and physical, disembodied and corporeal; bridging the gap between high and low, distant and adjacent, also between 
different disciplines and careers. It implies a more flexible, dynamic and mobile social and urban structure-another fantasy or utopia of the idealized democratic world.

Cinematic experiences of the city that are recorded in our mental movies are closely associated with the speed our human bodies travel through physical urban settings. Dull or exciting, stressful or relaxing, they are all our perceptions of the specific place and the journeys in between starting points and destinations. The accelerating urban experiences, formed not only by the physical modern vehicles, but also by social, economic and communicational media, have pushed us into a hyper-speed virtual environment and a hyper-activity subconscious world.

Digital technology, the net and VR provide us new visions and perceptions of speed, time and space, as well as the possibility of being here and now, and being then and somewhere else simultaneously. Travel speed has been maximized and re-interpreted as the speed of bits which is increasingly transforming our urban life, suggesting new patterns of infrastructure, distribution system, social relationships and city forms. Paul Virilio argues that today's society can be categorized by speed, one part still lives in an electrical world, the other in an electronic world, which implies the two different kinds of speed: relative speed (such as mechanical transportation) and absolute speed (such as transmission of information). To us, urban experience nowadays, especially in global metropolitan areas, runs toward an interdependent or overlapping effect of these two kinds of speed. It is because of the blur and combination of the traditional and advanced technologies in the physical beings we inhabit and utilize everyday, houses, cars, airplanes, cellular phones, computers, internet and telepresence services, co-exist and favor each other. The space-time experience of individual escapes from the ordinary graphic architectural representation (plan, section and elevation), and relates more with the integration of time and movement (both of people and bits).

\section{VIRTUALITY AND REALITY IN URBAN LIFE}

Telecommunication, electronic environments, digital technology and global networks increasingly affect the physical world we live in. Rapid advances in this technology will overthrow the regime of time and space that are familiar to us today. It is constructing interactions and dialogues between two different realms, one is the physical reality on a global scale, the other is the virtual reality of infinite construction site in cyberspace.

According to the estimation of Agenda 21, by the year 2025, the world's cities will accommodate $60 \%$ of its population, which might cause the deterioration of the existing urban problems, condensation, congestion, uneven distribution, over-use of natural resources, pollution, and imbalance of our environment. Digital technology, with its immaterial nature might offer us hopeful alternatives in designing the future cities. As William Mitchell argues in e-topia, "it necessitates us to extend the definitions of architecture and urban design to encompass virtual places as well as physical ones, software as well as hardware, and interconnection by means of telecommunications links as well as by physical adjacencies and transportation systems."

However, we are facing a dilemma of this technology. On one hand, we are searching for the immaterializing, minimized physical alternatives for the existing urban adversities; on the other hand, as this technology draws us from the reality, we are moving farther away from it-isolated and alienated human beings frozen in front of the computer terminals, lost in the illusion and fantasy created in the virtual space, leaving the problematic physical world unaltered behind.

In Iran, separation from physical world and move to virtual one is becoming more and more confusing, especially for younger generation. In order to remove this confusion, the new generation of urban planners and designers must learn how to create an efficient interaction of virtuality and reality in urban life. Before speculating on the interaction, a comparison of urban life in traditional Iranian cities with new type of relationships created in virtual world is necessary. There are many common characteristics both in physically constructed cities and virtual cities. The following is a brief comparison of these characteristics.

\section{Enclosure/Encryption}

In physically constructed cities, the enclosing surfaces of constituent spaces - walls, floors, ceiling, and roofs - provide not only shelter, but also privacy. Breaches in these surfaces gates, doors, and windows - have mechanisms to control access and maintain privacy: you can lock your doors or leave them open, lower the window shades or raise them. Spatial divisions and access control devices are deployed to arrange spaces into hierarchies grading from completely public to utterly private. Different societies have distinguished between public and private domains (and the activities appropriate to them) in differing ways, and cities have reflected these distinctions [5]. According to Lewis Mumford, domestic privacy was 'a luxury of the well-to-do' up until the $17^{\text {th }}$ century in the west [6].

Experts studying the characteristics of the Iranian cities, in trying to present an ideal pattern, have compared these cities with other examples or the cities that were built up contemporaneously with them, and have pointed to characteristics common among them which show the identity and uniqueness of these cities. One of the most dominant features in the Iranian city was the spatial hierarchy from completely public to utterly private. We have plenty of documents showing the fact that spatial hierarchy was very important in urban life of ancient Iranians. Persepolis is always considered as an ideal pattern of ancient Iranian city and the architectural manifestation of Iranian culture. Every spring, on the day of the vernal equinox, people of all creeds came from all corners of the empire to celebrate Nowruz. As a token of their allegiance, they each bore gifts and tributes. They passed through the Gateway of All Lands, and ascended the monumental double-reversing stairway, flanked by guards and representatives of the imperial domain, and atop the stairs, in the great hall, they offered their gifts and tributes to the King of Kings. Everybody who wanted to enter the palace and visit the king had to pass this hierarchy. The Persians knew the power and symbolism of architecture and used to take the benefit of it to emphasize the spatial and social hierarchy in 
almost all of built environments. Another manifestation of hierarchy from public space to private space was evident in the design of houses. Whether we choose to call it the face and the facade, the inner soul and the outer persona, zaher and baten, or andarun and birun, the fact remains that a certain dualism has long permeated Persian life. From the language of architecture and urban design to the linguistic tropes of the vernacular and the simple design of a Persian courtyard house, we can, if we look closely enough, discern this dualism. At the macro level, Persian culture has, succeeded in keeping its preIslamic kernel over the ages, and in each era, commensurate with the dominant force of the time, Persians adopted a suitable veneer. In their rendition, both Shiism and Sufism are manifestations of this kind of subterfuge for national survival. Historically, Persian cities were invariably introverted but with a complex and covert life, at odds with their usually austere outer appearance. The same pattern replicated itself within each self-contained, autonomous city neighborhood, or mahalleh, and then at the micro level, in each house, where high walls and a decided absence of windows separated a biruni and an andaruni. This house in particular has often been taken as a product of Islamic values, specifically as an attempt to separate the private quarters, and particularly the women from the gaze of the unsavory public and from the more public domain of patriarchy. This is an appealing interpretation, except for the fact that the phenomenon of the courtyard house already existed in the 20th century BC.

There is no rain or snow in cyberspace, so shelter is not a necessity, but privacy certainly is. So the technology for construction of virtual cities - just like that of bricks-andmortar ones - must provide for putting up boundaries and erecting access controls, and it must allow cyberspace architects and urban designers to organize virtual places into public-to-private hierarchies. Fortunately, some of the necessary technology does not exist. Most obviously, the rough equivalent of a locked gate or door, in cyberspace construction, is an authentication system. This controls access to virtual places( such as your electronic mail inbox) by asking for identification and a password. He trouble, of course, is that passwords - like keys - can be stolen and copied, or somehow extorted from the system manager who knows them all. Spatial hierarchy which was once very dominant in urban life of Iranian people, can be achieved in virtual communities too. In the virtual world a separate password should be used for different domains due to the applied policy of hierarchy or the level of privacy.

\section{Physical Transactions/Electronic Exchanges}

Historically, cities have provided places and zones for specialized business and different activities. There are many authoritative documents confirming the fact that the early cities and towns of eastern civilization (4th and 3rd millenniums BC.) had some zoning policies so that economic and trading activities were carried out in a particular district of the city. Archaeological discoveries provide reliable evidence of the remnants of the districts of tradesmen of two thousand years ago at Shoush. Specialization of occupations and the requirement of the primary societies brought about transactions and by the passage of time, a special place was established for this purpose that eventually formed bazaar. Bazaar, a traditional public space in Iranian cities, has always accommodated a great section of commercial activities in urban life. The urban bazaar historically has been the heart of the Iranian town. In virtually all towns the bazaar is a covered street, or series of streets and alleyways, lined with small shops grouped by service or product. One part of the bazaar contains the shops of cloth and apparel dealers; another section those of carpet makers and merchants; and still another, the workshops of artisans making goods of copper, brass, or other metals, leather, cotton, and wool. In small towns the bazaar might be the equivalent of a narrow, blocklong street; in the largest cities, such as Tehran, Isfahan, Mashad, Tabriz, and Shiraz, the bazaar is a warren of streets that contains warehouses, restaurants, baths, mosques, schools, and gardens in addition to hundreds and hundreds of shops [7].

In the traditional cities of Iran, all of the activities were face to face and the commercial relations were all based on physical transfer of cash and direct delivery of goods and services.

But where electronic funds transfer can substitute for physical transfer of cash, and direct delivery from the warehouse can replace carrying the goods home from store, the counter can become a virtual one. Television home shopping networks first exploited this possibility.

In traditional cities, transaction of daily business was accomplished literally by handing things over; goods and cash crossed store counters, contracts were physically signed, and perpetrators of illegal transaction were sometimes caught in the act. But in virtual cities, transactions reduce to exchanges of bits [5].

\section{Street Maps/ Hyperplans}

Ever since ancient times, doorways and passageways have joined together the rooms of buildings, webs and grids os streets have connected buildings to each other, and roads have linked cities. These physical connections provided access to the places where people lived, worked, worshipped, and entertained themselves.

For Iranians, man was a profoundly social creature, and although this attitude can be found in the writings of poets and intellectuals, it is nowhere expressed more explicitly than in their architecture and their city planning. Iranian city planning is based on the idea that the form of cities, the shape of streets and spaces, reflected the people who inhabited them as well as their culture, religion and interests. Thus, the location of public spaces of the city and the network of circulation channels were of great importance for Iranian city planners. The visible and hidden geometry of urban circulation patterns and their role in formation of urban structure was a key factor in cultural and social identity of urban life in Iranian cities [8].

The network of World Wide Web provides access and constructs a virtual rather than physical world of places and connections; the places are called pages and they appear on screen, and the connections - called hyperlinks - allow us to jump from page to page by clicking on highlighted text or icons. The astonishing thing is that a WWW page displayed on screen may originate from a server located anywhere in the 
Internet. We can log into machines scattered around the world. But as we see it, we jump almost instantaneously from virtual place to virtual place by following the hyperlinks that programmers have established - much as we might trace a path from piazza to piazza in a great city along the roads and boulevards that a planner had provided [5].

\section{Human laws/coded conditionals}

The study of urban history reveals that different kinds of laws and regulations have acted as the governing rules of urban environments. Ever since the earliest settlements of humankind, cities have been controlled by regulatory laws which were derived from different ideologies. Traditional cities of Iran were no exception. During the pre-Islamic period different dynasties applied different regulations due to cultural, political, and geographical characteristics of their territory. After the advent of Islam, Islamic laws were the most prevailing laws governing the urban life, and even now that modernization has changed the face of Iranian cities, Islamic laws still govern the urban life [9].

Out there on the electronic frontier, code is the law. The rules governing any computer-constructed microworld - of a video game, of your personal computer desktop, of a word processor window, of an automated teller machine, or of a chat room on the network - are precisely and rigorously defined in the text of the program that constructs it on our screen.

For citizens of cyberspace, computer code - arcane text in highly formalized language, typically accessible only to a few privileged high-priests - is the medium in which intentions are enacted and designs are realized, and it is becoming a crucial focus of political contest [5].

\section{CONCLUSION}

New technologies of communication and information exchange have engendered a situation in which the urban site can no longer be thought of primarily in terms of its geography. While modern cities have become fragmented and discontinuous spatially, they are connected in vast invisible networks where information, images and money flow freely from location to location. As social philosopher Paul Virilio wrote, "The representation of the contemporary city is no longer determined by a ceremonial opening of gates, by a ritual procession or parades nor by a succession of streets and avenues. From now on architecture must deal with the advent of a 'technological space-time."'

The impact of these new technologies on our cities has been profound, contributing to a dismantling of the historic city and the reconstruction of urban life in entirely new, free-floating forms. Increasingly, our thinking about the city must confront the fact that we live not simply in places, but in cities constructed as simulations and complex webs. Public life has moved from Main Street and the Malt shop to the hyperenvironment of the shopping mall and the surface of the video screen. Rapid advances in this technology will overthrow the regime of time and space that are familiar to us today. It is constructing interactions and dialogues between two different realms, one is the physical reality with local identity, the other is the virtual reality of infinite construction site in cyberspace.

In developing countries like Iran, this interaction is more confusing and even problematic. Iran, a country with an old history and diverse traditions of urban life, now faces a global situation in which all traditions, localities and old believes must be ignored. New trends in younger generation and bias towards old traditions in older generation creates a gap between them. In order to deal with this contradiction and duality, the new generation of urban planners and designers must try to further reinforce the interaction between two different realms, one is the physical life, the other is virtual world.

In this paper some basic issues related to the new situation were reviewed, but it is necessary to accomplish further research which will engage leading thinkers and writers in philosophy, social sciences, literature, and the design professions in examining such questions as, What will be the form of cities in the future? How are new technologies altering our concepts of public life and public space? What is the architecture of the virtual city? Who shall write the software that increasingly structures our daily lives? How do we resolve the tension between the concept of the historic city and the virtual communities of the future? What kind of rules should be applied for management of future cities?

\section{References}

[1] M. Batty, P. Longley, "The fractal city," in Urban Environments, 2nd ed. E. G. Mapelli, Ed. West Sussex: WILEY-ACADEMY, 2001, p. 192.

[2] M. Mozayeni, "Towards a new urbanization in Iran," unpublished.

[3] G. Borradori, "Against the technological interpretation of virtuality, " in Urban Environments, 2nd ed. E. G. Mapelli, Ed. West Sussex: WILEY-ACADEMY, 2001, p. 110.

[4] C. L. Morgan, G. Zampi, Virtual Architecture. London : B. T. Batsford Ltd., 1995, ch. 1.

[5] W. Mitchel, "Soft cities," in Urban Environments, 2nd ed. E. G. Mapelli, Ed. West Sussex : WILEY-ACADEMY, 2001, pp. $202-$ 203.

[6] L. Mumford, The City in History. Harcourt Brace and World, New York, 1961, p. 384

[7] M. S. Moosavi, "Bazaar and its role in the development of Iranian traditional cities," presented at the First International Congress of Islamic Archeology, Istanbul, Turkey, April 8-10, 2005.

[8] M. S. Moosavi, "An approach to urbanization in ancient Iran," unpublished.

[9] M. Kiani, A History of Urbanization in Iran. $2^{\text {nd }}$ ed. Tehran University Publications, 1998, ch. 3. 